\title{
Letters
}

\section{Use of statins}

See editorial by Muldoon

\section{Adequacy of SMAC's statement should be judged by clinicians, not health economists}

EDITOR-Freemantle et al's editorial argues that the statement on the use of statins in coronary heart disease prepared by the Standing Medical Advisory Committee and issued recently by the NHS Executive is "simply inadequate." 2 The adequacy or otherwise of advice depends on the context in which it was issued and whether it is appropriate for the purpose.

The context was the dramatic increase in the prescribing of statins since the publication of two landmark randomised controlled trials (the 4S (Scandinavian simvastatin survival study) ${ }^{3}$ and WOSCOPS (the west of Scotland coronary prevention study $)^{4}$ ). Guidance issued by the European Society of Cardiology advised treating those of the population with a risk of coronary heart disease of $\geqslant 2 \%$ a year, ${ }^{5}$ and others have advocated treating those with a risk of $\geqslant 1.5 \%$. The annual cost to the NHS of treating all people with coronary heart disease and those with $\mathrm{a} \geqslant 1.5 \%$ risk of developing symptoms would be of the order of $£ 3.5 \mathrm{bn}$.

Most statins will be prescribed by general practitioners, and it was for them that authoritative but concise interim advice was primarily needed. The Standing Medical Advisory Committee convened a representative working party, including health economists. Its views were unanimous and, as the statement makes clear, were based on careful consideration of the "clinical effectiveness, cost effectiveness and long term safety of statins." The current information on statins is better than that available for most new drugs, although data on comparative cost effectiveness are incomplete. The priority for the NHS is to treat those who can derive appreciable benefit from statins but to obviate inappropriate prescribing. It was not assumed that all people in the three priority groups would necessarily be treated with a statin, but if the statement were followed then the resources available would be targeted most effectively.

To be concise the statement could not be comprehensive or comprehensively referenced. Key references on clinical effectiveness were provided, but anyone wishing for further information was advised to contact a senior medical officer in the NHS Executive, which many, but not Freemantle et al, have done.
The adequacy or otherwise of the Standing Medical Advisory Committee's statement should be judged not by health economists but by general practitioners and other clinicians. Its overall effectiveness should be judged against the rise in the drugs bill for statins, the appropriateness of future prescribing, and-possibly most importantly-the impact of statins on mortality from coronary heart disease.

Peter Enoch Chairman, Standing Medical Advisory Committee

Littlewick Medical Centre, Ilkeston, Derbyshire DE7 5PR

1 Freemantle N, Barbour R, Johnson R, Marchment M, Kennedy A. The use of statins: a case of misleading prioriKennedy A. The use of statins: a ca
ties? BMJ 1997:315:826-8. (4 Oct)

ties? BMJ 1997;315:826-8. (4 Oct.)

2 Winyard G. SMAC statement on use of statins. London: Department of Health, 1997. (EL(97)41 HCD 750 IP Aug 97.)

3 Scandinavia Simvastatin Study Group. Randomised trial of cholesterol lowering in 4444 patients with coronary heart disease: the Scandinavian simvastatin survival study (4S). Lancet 1994;344:1383-9.

4 Shepherd J, Cobbe SM, Ford I, Isles CG, Lorimer AR, Macfarlane PW, et al. for the West of Scotland Coronary Prevention Group (WOSCOPS). Prevention of coronary heart disease with pravastatin in men with hypercholesterolemia. N Engl J Med 1995:333:1301-7.

5 rolemia. N Engl J Med 1995;333:1301-7. Pyorala K, de Backer G, Graham I, Poole-Wilson P, Wood $\mathrm{D}$ on behalf of the Task Force of the European Society of Cardiology, European Atherosclerosis Society, and European Society of Hypertension. Prevention of coronary heart disease in clinical practice. Eur Heart J 1994;15: 1300-31.

\section{Trent institute's research working group} has produced guidance for purchasers

EDITOR-Freemantle et al's editorial on statins makes important points about the desirability of linking the benefits of new treatments to their costs to allow sensible decisions on health purchasing. ${ }^{1}$ Nevertheless, the attack on the Standing Medical Advisory Committee's guidance seems harsh. The quality of evidence on the effectiveness of statins, and its use by the committee, makes for guidance that is better than that for nearly every other treatment one can imagine. It is not unreasonable for the committee to leave the costing work to others.

The authors of the editorial also ignore the fact that others have addressed the issues that they raise and that further work is being undertaken. Trent Institute for Health Services' research working group on acute purchasing, which I chair, produces a series of guidance reports for purchasers, and one relates to statins. ${ }^{2}$ That report sets out the gross and net impacts on costs for a typical district; sets out the likely impact on other services for a typical district; estimates life years likely to be gained at different levels of intervention (and therefore costs); and compares costs per life year gained with statin treatment with those for activities already undertaken in the NHS.

Trent regional executive has commissioned further work from the School of Health and Related Research at the University of Sheffield to develop a computer model ("statins toolkit"). This will allow health authorities to examine the consequences for health outcomes and resource use for their locality of four options: not using statins; using them in secondary prevention (in terms of myocardial infarctions and other events prevented); using them in primary prevention (at a $4.5 \%, 3 \%$, and $1.5 \%$ annual risk of a coronary event); and phasing in their use over years.

The main issue highlighted by the editorial is the need to coordinate effectively the guidance emanating from a variety of sources so that harassed purchasers know where to locate the best advice.

R L Akehurst Professor of health economics School of Health and Related Research, University of Sheffield, Sheffield S1 4DA

\section{Advice to authors}

We receive more letters than we can publish:we can currently accept only about one third. We prefer short letters that relate to articles published within the past four weeks. We also publish some "out of the blue"letters, which usually relate to matters of public policy.

When deciding which letters to publish we favour originality, assertions supported by data or by citation, and a clear prose style. Letters should have fewer than 400 words (please give a word count) and no more than five references (including one to the BMJ article to which they relate);references should be in the Vancouver style. We welcome pictures.

Letters, whether typed or sent by email, should give each author's current appointment and full address. Letters sent by email should give a telephone and fax number when possible. We encourage you to declare any conflict of interest. Please send a stamped addressed envelope if you would like to know whether your letter has been accepted or rejected.

We may post some letters submitted to us on the world wide web before we decide on publication in the paper version. We will assume that correspondents consent to this unless they specifically say no.

Letters will be edited and may be shortened. 
1 Freemantle N, Barbour R, Johnson R, Marchment M, Kennedy A. The use of statins: a case of misleading priorities? BMJ 1997;315:826-8. (4 October.)

2 Working Group on Acute Purchasing Statin therapy/HMG Working Group on Acute Purchasing. Statin therapy/HMG coA reductase inhibitor treatment in the prevention of coronar heart disease. Sheffield: Trent Institute for Health Service of Sheffield, 1996. (Guidance note for purchasers 96/04.)

\section{Other, cheaper and simpler, measures should be tried first}

EDITOR-We agree with Freemantle et al's editorial pointing out that the Standing Medical Advisory Committee's advice on statins is deficient and that there is considerable potential for harm outweighing the good. ${ }^{1}$ The committee's advice is based on multifactorial risk assessment but fails to recognise the range of interventions known to be effective. Thus smoking cessation, aspirin, $\beta$ blockers, and angiotensin converting enzyme inhibitors have important roles in secondary prevention.

While the individual's risk is important, so too is the population impact of treatment interventions. We know that smoking cessation and aspirin are cheap and safe, so is it not appropriate to use them first? Unfortunately, these simple measures are not used a lot of the time. ${ }^{2}$ The addition of $\beta$ blockers is the next most cost effective intervention, and this has the merit of not needing repeated diagnostic tests.

We suspect that the marginal benefit of adding statins is small and that the number needed to treat to prevent a coronary event or death will be large. We agree with the editorial that the effort and resources expended in cholesterol management could distract patients and their doctors from the more cost effective interventions. We note that in the $4 \mathrm{~S}$ trial (Scandinavian simvastatin survival study) $63 \%$ of high risk patients were not taking aspirin and $43 \%$ were not taking a $\beta$ blocker. ${ }^{3}$ It would be valuable to know how the impact of statins varied between these patients and those who were taking aspirin or $\beta$ blockers, or both, and it is to be hoped that such an analysis will be forthcoming. Our concern is that the greatest improvement in the health of our population should be secured by the best use of available resources.

Peter Sheridan Consultant in public health medicine Peter Savege Primary care medical adviser Sue Silverman Pharmaceutical adviser

Enfield and Haringey Health Authority, Barnet,

Hertfordshire EN4 0DR

1 Freemantle N, Barbour R, Johnson R, Marchment M, Kennedy A. The use of statins: a case of misleading priorities? BMJ 1997;315:826-8. (4 October.)

2 Eccles M, Bradshaw C. Use of secondary prophylaxis against myocardial infarction in the north of England. BMJ against myocard

3 Scandinavian Simvastatin Survival Group. Randomised trial of cholesterol lowering in 4444 patients with coronary heart disease: the Scandinavian simvastatin survival study (4S). Lancet 1994;344:1383-9

\section{In New Zealand, subsidy of statins is} limited to particular groups of patients

EDITOR-The issues brought forward in the editorial by Freemantle et al are not limited to Britain. ${ }^{1}$ Countries and doctors all over the world are struggling with the question of which patients should be treated with statins.
In New Zealand the government funding agency (the Pharmaceutical Management Agency (PHARMAC)) made a decision on treatment with statins that was based partly on clinical advice from an expert subcommittee and partly on a cost utility analysis. This decision limits subsidy of statins to the following groups:

- patients with clinically proved ischaemic heart disease with a total cholesterol concentration of $>6.0 \mathrm{mmol} / \mathrm{l}$;

- patients who have had coronary artery bypass grafting with a total cholesterol concentration of $>5.5 \mathrm{mmol} / \mathrm{l}$;

- patients with a family history of ischaemic heart disease, with a proved ischaemic stroke, with a history of ischaemic attack, with a history of intermittent claudication, or with established diabetic nephropathy who have a total cholesterol concentration of $>6.0 \mathrm{mmol} / \mathrm{l}$;

- all other patients with a total cholesterol concentration of $>9.0 \mathrm{mmol} / \mathrm{l}$.

As a result of a recent negotiated reduction in cost, all available statins in New Zealand (fluvastatin, pravastatin, and simvastatin) are now subsidised at the same daily cost (NZ\$1.05; 42p); the cost per quality adjusted life year is estimated to be NZ\$10 000 $(£ 4150)$ or less for treatment of the designated groups. Under the previous costings, the cost per quality adjusted life year even for patients with greatest benefit (those with clinically proved ischaemic heart disease with a total cholesterol concentration of $>7.0 \mathrm{mmol} / \mathrm{l})$ was $\mathrm{NZ} \$ 28000$ (£11 600).

Our analysis suggests that for patients requiring primary prevention who are at very high risk, such as those in WOSCOPS (west of Scotland coronary prevention study), the cost per quality adjusted life year is around NZ\$15000 (£6200) at the new subsidy. It would have been around NZ\$60 $000(£ 24900)$ at the previous subsidy. Clearly, the price of statins and the baseline risk of the patient have an important effect on the cost effectiveness of the programme.

We agree with Freemantle et al that, at the present time, statins should only be used to treat patients judged to be at risk similar to or greater than that of the patients in the $4 \mathrm{~S}$ trial (Scandinavian simvastatin survival study). An international discussion on how to make such decisions based on solid cost effectiveness data is needed. This would facilitate the process for individual countries in deciding what they can afford.

Win Bennett Medical director

Wayne McNee Therapeutic group manager Scott Metcalfe Public health physician PHARMAC, PO Box 20-253, Wellington, New Zealand

James M Wright Associate professor of clinical pharmacology

University of British Columbia, Vancouver, BC, Canada

1 Freemantle N, Barbour R, Johnson R, Marchment M, Kennedy A. The use of statins: a case of misleading priorities? BMJ 1997;315:826-8. (4 October.)
Guidelines need to concentrate on reducing overall cardiovascular risk

EDITOR-We agree with Freemantle et al that all cases of established atheroma need treatment, ${ }^{1}$ as established in the $4 \mathrm{~S}$ (Scandinavian simvastatin survival study) and CARE (cholesterol and recurrent events) study. Patients who have had coronary artery bypass surgery need even more aggressive treatment. $^{2}$ We disagree with an analysis based solely on deaths avoided. The NHS has no effect on the outcome total mortality. Any cost effectiveness study of lipid reduction by the NHS needs to focus on morbidity and efficiency of care (events avoided, procedures saved, hospital stays reduced). Deaths postponed are a welcome bonus. The statin studies are convincing and suggest a prevention rate of 1 in 13-25 (not 1 in 55 as the authors say), at a cost of $£ 5000-8000$. $^{3}$

The implications for primary care of the prescription of statins in men after WOSCOPS (west of Scotland coronary prevention study) are huge. The effects will be greater once large pooled single agent studies show the benefits of lipid reduction in women, elderly people, patients with strokes, and those with diabetes. Pilot data on the diabetic subgroup in the $4 \mathrm{~S}$ study suggest large reductions in events. ${ }^{4}$ The primary prevention Sheffield tables recommended (based on a 10 year risk of coronary heart disease of $30 \%$ ) are at variance with the international consensus ( 10 year risk of $20 \%$ ). Many would disagree with them.

The likely cost of statins is horrendous. It is the bill for 50 years of neglect of advice on diet and lifestyle. Statins are one of the most effective treatments available for reducing mortality from and morbidity of atheroma. Are we to deny patients effective treatment for coronary disease because it is expensive? Or should we negotiate better terms nationally or use class competitors, since all forms of lipid reduction reduce events? Maybe we ought to consider the whole cardiovascular drug budget. The idea that lipids and mild hypertension should be managed separately is antiquated. Recommendations by the World Health Organisation state that mild hypertension ( $<180 / 105 \mathrm{~mm} \mathrm{Hg}$ ) should be managed as part of overall cardiovascular risk. ${ }^{5}$ The treatment of hypertension is less effective in terms of events (1 in 131 events). Should we switch priorities? It is an open question.

The Standing Medical Advisory Committee's guidelines need complete revision. Their aim should be to guide the whole medical profession in how to reduce overall cardiovascular risk most effectively, not just concentrate on one aspect.

A S Wierzbicki Senior lecturer in chemical pathology St Thomas's Hospital, London SE1 7EH

T M Reynolds Consultant chemical pathologist Burton Hospitals, Burton on Trent DE13 0RB

1 Freemantle N, Barbour R, Johnson R, Marchment M, Kennedy A. The use of statins: a case of misleading priorities? BMJ 1997;315:826-8. (4 October.)

2 Post-Coronary Artery Bypass Graft Trial Investigators. The effect of aggressive lowering of low-density lipoprotein cholesterol levels and low dose anticoagulation on 
obstructive changes in saphenous vein coronary bypass grafts. N Engl J Med 1997;336:153-62.

Johanneson M, Jonsson B, Kjekshus J, Olsson AG, Pedersen TR, WedelH on behaf of the Scandina Pedersen TR, Wedel Hon behall of he Scandinavian Simvastatin Survival Study Group. Cost-effectiveness of with statin treatnent lowe cholesterol levels in patient

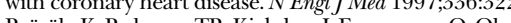

4 Pyöräla K, Pedersen TR, Kjekshus J, Faergeman O, Olsson AG, Thorgeirsson G. Cholesterol lowering with simvastatin improves prognosis of diabetic patients with coronar heart disease. Diabetes Care 1997;20:614-20.

5 Chalmers J, Zanchetti A. The 1996 report of a World Health Organisation expert panel on hypertension control.J Hypertens 1996;14:929-33.

\section{Faculty's advice does refer to cost effictiveness}

EDITOR-In their editorial on the Standing Medical Advisory Committee's guidance on the use of statins, ${ }^{12}$ Freemantle et al also criticise recent advice from the Faculty of Public Health Medicine addressed to local directors of public health. ${ }^{3}$ Unfortunately, they do not seem to have read the faculty's advice very carefully. While they correctly state that the faculty advocates locally developed guidelines that target high risk patients and consider issues of cost effectiveness, they then go on to contradict themselves by saying that the faculty's advice makes no reference to cost effectiveness.

In fact, the faculty's advice deals extensively with costs as well as effectiveness and clearly states that local policies should take account of the resources available. The faculty recognises that the resources that each purchaser wishes to allocate to pharmacological lipid lowering "will depend on local priorities within coronary heart disease prevention, cardiology and total health care expenditure" and that this decision "should be taken by consensus among the stakeholders." Cost effectiveness studies on the use of statins in practice are currently limited, and none so far has included such crucial aspects as prescribers' compliance with local policy, patients' compliance with treatment, or the cost and effectiveness of newer statins.

While the faculty agrees with Freemantle et al in their assertion that more evidence on the cost effectiveness of statins is needed, we believe firmly that enough is already known to allow local decision makers to issue policies on lipid lowering based on absolute risk. In view of the rapidly escalating costs of widespread inappropriate and ineffective prescribing of statins, this task is urgent and cannot wait until all the evidence is in

Alan Maryon Davis Convener, cardiovascular working group

Faculty of Public Health Medicine, 4 St Andrews Place, London NW1 4LB

1 Standing Medical Advisory Committee. The use of statins. London: Department of Health, 1997. (11061 HCD August 97(04).)

2 Freemantle N, Barbour R, Johnson R, Marchment M, Kennedy A. The use of statins: a case of misleading priorities? BMJ 1997;315:826-8. (4 October.)

3 Faculty of Public Health Medicine. Lipid lowering-how to draw the line. Guidance for directors of public health. London: FPHM, 1997.

Results of different studies differed greatly EDITOR-We do not agree with Freemantle et al that it is possible to be sure that the patients in $4 \mathrm{~S}$ (Scandinavian simvastatin survival study) were at greater risk than those in the CARE (cholesterol and recurrent events) study. ${ }^{1}$ All the participants in the CARE study had had a myocardial infarction. ${ }^{2}$ In contrast, in $4 \mathrm{~S}$, a fifth of the patients had angina only ${ }^{3}$ and were at a lower risk of major coronary events than the patients with myocardial infarction. ${ }^{4}$ The maximum age was 75 in the CARE study and 70 in 4 S; the incidence of myocardial infarction increases with age.

There are important differences in the results of these trials. In $4 \mathrm{~S}$ the benefit from simvastatin progressively increased up to serum triglyceride concentrations of $2.5 \mathrm{mmol} / \mathrm{l}$ (the upper limit for entry into 4 S). ${ }^{5}$ In contrast, in the CARE study there was no significant benefit at triglyceride concentrations above $1.6 \mathrm{mmol} / \mathrm{l}^{2}$ Benefit was observed throughout the range of decrease in cholesterol concentrations in $4 \mathrm{~S}$ whereas in the CARE study there was no significant benefit below a low density lipoprotein concentration of $3.2 \mathrm{mmol} / \mathrm{l}^{2}{ }^{3}$

The incidence of events in the placebo group in the CARE study may have been reduced by the lower low density lipoprotein cholesterol concentration on entry and a wider use of other effective drugs (for example, aspirin and angiotensin converting enzyme inhibitors). However, the benefit in the pravastatin group may also have been enhanced by these measures. If the results in the CARE study reflect a lower vascular risk why is the reduction in absolute risk marginally better in WOSCOPS (west of Scotland coronary prevention study), a trial in healthy subjects (see Freemantle et al's table ${ }^{1}$ )?

There are major differences in cost. The CARE study and WOSCOPS used pravastatin $40 \mathrm{mg}$ /day. In $4 \mathrm{~S}$ only $37 \%$ of patients were taking $40 \mathrm{mg}$ simvastatin/day; the rest were taking $20 \mathrm{mg} /$ day. In Britain the cost of both drugs is comparable at $20 \mathrm{mg}$ and $40 \mathrm{mg}$ doses. Furthermore, if the target concentrations were not achieved in the CARE study, cholestyramine was added to the pravastatin. It is not clear how many patients required cholestyramine.

All statins may not be equal, especially in terms of cost needed to achieve clinically relevant end points. Consideration of cost benefit is further complicated by the reduction in admissions and procedures as a result of treatment ${ }^{2}{ }^{3}$; cost calculations are not readily undertaken. Whether guidelines should suggest "first choice" statins remains a sensitive ethical issue.

D P Mikhailidis Reader, department of chemical pathology and human metabolism

A F Winder Professor

Royal Free Hospital and School of Medicine (University of London), London NW3 2QG

1 Freemantle N, Barbour R, Johnson R, Marchment M, Kennedy A. The use of statins: a case of misleading priorities? BMJ 1997;315:326-8. (4 October.)

Sacks FM, Pfeffer MA, Moye LA, Rouleau JL, Rutherford JL, Rutherford J, Cole TG, et al. The effect of pravastatin on coronary events after myocardial infarction in patients with

3 Scandinavian Simvastatin Survival Study Group. Randomised trial of cholesterol lowering in 4444 patients with coronary heart disease: the Scandinavian simvastatin survival study. Lancet 1994;344:1383-9.
4 Pedersen TR, Kjekshus J, Olsson AG, Berg K, Faergeman $\mathrm{O}$, Haghfelt $\mathrm{T}$, et al Scandinavian simvastatin survival study. Lancet 1994:344:1767-8.

5 Pedersen TR, Kjekshus J, Berg K, Faergeman O, Miettinen Pedersen TR, Kjekshus J, Berg K, Faergeman O, Miettinen , Olsson AG. Lipid changes and reductions in the incidence of major coronary heart disease events in the 1997;130(suppl):S7.

\section{Glasgow has already produced strategy} for treatment

EDITOR-Freemantle et al are correct in emphasising that costs and benefits must be linked when new treatments are considered, but they then go on to ignore this advice. ${ }^{1}$ They make the all too common error of emphasising mortality benefits while excluding the impact of treatment on morbidity. This is looking at only one side of the cost effectiveness equation, where effectiveness reflects mortality benefits and costs avoided reflect the impact of treatment on morbidity. Yes, 4S (Scandinavian simvastatin survival study) tells us that we may need to treat 30 patients for five years to prevent one death, but the picture looks completely different when it is realised that 16 admissions to hospital for myocardial infarction, six admissions for angina, 1.5 admissions for heart failure, two strokes or transient ischaemic attacks, and nine revascularisation procedures will also be avoided. ${ }^{2}$ Indeed, a total of 34 fewer admissions for cardiovascular reasons and 347 fewer hospital bed days can be expected. ${ }^{2}$ Not surprisingly, therefore, cholesterol lowering treatment is likely to be cost effective in a population similar to that in $4 \mathrm{~S}$. Freemantle et al are wrong in stating that no formal information on cost effectiveness is available. There are at least three published economic analyses of $4 \mathrm{~S}$, and the estimated incremental cost effectiveness ratio is around $£ 5000-10000$ per life year gained in Britain. ${ }^{3}$ We have supported this conclusion in an unpublished analysis, estimating that the direct incremental cost of treatment is $£ 2083$ per patient over 10 years (that is, $£ 208$ a year or $57 \mathrm{p}$ a day). Similar, detailed, analyses of the benefits and costs of primary prevention are widely available. ${ }^{4}$

Health boards such as Glasgow have already produced a strategy and accompanying guidelines to target and treat cost effectively, in an evidence based way, those patients who have most to gain from cholesterol lowering treatment. $^{5}$

J McMurray Consultant cardiologist

MRC Clinical Research Initiative in Heart Failure, University of Glasgow, Glasgow G12 8QQ

A McGuire Professor of health economics

M Raikou Research fellow

Department of Economics, City University, London EC1V 0HB

C Morrison Consultant in public health Scottish MONICA Project, Royal Infirmary, Glasgow G31 2ER

Freemantle N, Barbour R, Johnson R, Marchment M, Kennedy A. The use of statins: a case of misleading prioriies? BMJ 1997;315:826-8. (4 October.)

2 Pedersen TR, Kjekshus J, Berg K, Olsson AG, Wilhelmsen Pedersen TR, Kjekshus J, Berg K, Olsson AG, Wilhelmsen
L, Wedel H, et al. Cholesterol-lowering and the use of health-care resources: results of the Scandinavian simvahealth-care resources: results of the Scandinavian
statin survival study (4S). Circulation 1996;94:63.

3 Jonsson B, Johannesson M, Kjekshus J, Olsson AG, Pedersen TR, Wedel H. Cost-effectiveness of cholesterollowering-results from the Scandinavian simvastatin survival study (4S). Eur Heart J 1996;17:1001-7. 
4 Caro J, Klittich W, McGuire A, Norrie J, Ford I, McMurray $\mathrm{J}$, et al. The cost effectiveness of preventinig initial coronary events with pravastatin: results of the west of Scotland coronary preention study economic analysis. Atherosclerosis coronary pre

5 Morrison C, McMurray J. Lipid-lowering strategies for thee Morrison C, McMurray J. Lipid-lowering strategies for thee
prevention of coronary heart disease. Clin Sci 1997;92:431

\section{Health authorities must work with clinicians to target statins}

EDITOR-We agree with some of Freemantle et al's views on the use of statins, but the authors seem to be more concerned with the financial implications of using statins than with the cost effective treatment of coronary heart disease. ${ }^{1}$ They assert that the Standing Medical Advisory Committee's report $^{2}$ ignores cost effectiveness and that enthusiasts for cholesterol lowering drugs "may do more harm than good through making savings in more cost effective areas," but they fail to provide evidence in support of their claims. Indeed, available estimates suggest that the cost effectiveness of using statins, both in secondary prevention of coronary heart disease and in primary prevention in those at high risk, is reasonable in comparison with that of alternative methods of treating coronary heart diseases and other claims on available resources (table).

The population impact of use of statins is likely to be much greater than that of coronary artery surgery. ${ }^{4}$ Waiting time pressures for coronary artery surgery have encouraged an increase in provision, although increasing use of statins may have had more impact on health. The authors do not consider the other beneficial effects of statins-for example, on non-fatal coronary heart disease events or stroke.

Our experience suggests that general practitioners, rather than being "overwhelmed by the size of the proposed change," are keen to implement evidence based approaches to prescribing in coronary heart disease. The challenge for

Published valuations of cost per life year gained for selected healthcare interventions

\begin{tabular}{|c|c|}
\hline Intervention & $\begin{array}{c}\text { Cost per life } \\
\text { year gained }(£)\end{array}$ \\
\hline $\begin{array}{l}\text { Thrombolytic drugs in myocardial } \\
\text { infarction }\end{array}$ & 3000 \\
\hline $\begin{array}{l}\text { Nicotine gum for smokers } \\
\text { (men aged 35-39) }\end{array}$ & 3934 \\
\hline $\begin{array}{l}\text { Coronary care unit provision for patients } \\
\text { with myocardial infarction }\end{array}$ & 4974 \\
\hline $\begin{array}{l}\text { Secondary prevention of CHD with } \\
\text { statins }\end{array}$ & 5100 \\
\hline $\begin{array}{l}\text { Primary prevention of } \mathrm{CHD} \text { with statins } \\
\text { (people with risk } \geqslant 3 \% \text { ) }\end{array}$ & 7400 \\
\hline $\begin{array}{l}\text { Breast cancer screening } \\
\text { (women aged 45-65) }\end{array}$ & 8417 \\
\hline Cervical cancer screening & 9070 \\
\hline $\begin{array}{l}\text { Intensive care treatment for patients with } \\
\text { multiple trauma }\end{array}$ & 9977 \\
\hline $\begin{array}{l}\text { Use of neonatal intensive care unit } \\
\text { (infants with birth weight } \leqslant 999 \mathrm{~g} \text { ) }\end{array}$ & 11400 \\
\hline Kidney transplantation & 17400 \\
\hline Haemodialysis & 27000 \\
\hline
\end{tabular}

$\mathrm{CHD}=$ Coronary heart disease.

From report of Working Group on Acute Purchasing. ${ }^{3}$ health authorities is to work with clinicians to target the use of statins to those at high risk. In Dudley, because of a combination of a district-wide clinical audit process facilitated by the local medical audit advisory group, guidelines, and intervention by the prescribing adviser, $85 \%$ of patients with a history of myocardial infarction are now receiving low dose aspirin. A similar approach will be adopted to target use of statins, initially in secondary prevention.

Finally, we share concern that advice to implement the advisory committee's document in the absence of additional resources may be seen as "passing the buck." A recent survey that we did of district prescribing committees showed considerable similarity in the main prescribing challenges facing health authorities ${ }^{5}$; this illustrates the desirability of a national approach in important therapeutic areas. We therefore welcome the national approach adopted in the advisory committee's guidance and trust that the size of annual increases in prescribing allocations to health authorities will fully reflect this national priority.

\section{Andrew P Wakeman Medical adviser}

Robert H Leach Pharmaceutical adviser

Dudley Health Authority, Dudley, West Midlands DY1 2DD

1 Freemantle N, Barbour R, Johnson R, Marchment M, Kennedy A. The use of statins: a case of misleading priorities? BMJ 1997;315:826-8. (4 October.)

2 Standing Medical Advisory Committee. The use of statins. London: Department of Health, 1997. (11061 HCD Aug $97(04)$.)

Working Group on Acute Purchasing. Statin therapy/HMG $c o A$ reductase inhibitor treatment in the prevention of coronary heart disease. Sheffield: Trent Institute for Health Services Research, University of Sheffield, 1996.

4 European Coronary Surgery Study Group. Long term results of prospective randomised study of coronary artery bypass surgery in stable angina pectoris. Lancet bypass surgery

5 Wakeman AP, Leach RH. Joint prescribing committees: Wakeman AP, Leach RH. Joint prescribing committees:
characteristics, progress and effectiveness. Health Trends (in press).

\section{More evidence is needed for guidelines}

EDITOR-Freemantle et al make some good points about the Standing Medical Advisory Committee's guidelines on the use of statins. ${ }^{1}$ Perhaps the weakest point of the guidelines is the statement that patients with peripheral vascular or symptomatic carotid disease have a risk of major coronary events of about $3 \%$ a year. Where is the evidence to support this assertion?

The authors of the Sheffield tables quote a risk of $4 \%,{ }^{2}$ citing the UK-TIA (United Kingdom transient ischaemic attack) study. ${ }^{3}$ In fact, the event rate was about $3 \%$ a year, but a fifth of the patients had existing ischaemic heart disease and the study did not separate these from patients without ischaemic heart disease, who may be at lower risk. The $4 \%$ is probably a quote from a study by Heyman et al of 390 patients admitted to hospital with transient ischaemic attack. ${ }^{4}$ But $30 \%$ of these had angina and $26 \%$ had had myocardial infarcts. It is not clear what overall proportion had existing ischaemic heart disease (between 30\% and $56 \%$ ), but again the results did not separate these from patients without prior ischaemic heart disease (although the authors comment that prior ischaemic heart disease was a good predictor of subsequent coronary events).

For peripheral vascular disease the Sheffield article cites a study of 67 patients with large vessel peripheral arterial disease. ${ }^{5}$ This, however, included only eight people with symptomatic peripheral arterial disease who did not have other cardiovascular disease at baseline. It seems unwise to make generalisations on the basis of a sample of eight.

There are many other studies of patients with carotid and peripheral vascular disease that follow up coronary events, but few separate prognosis for those with existing ischaemic heart disease and those without. The risk of a coronary event might well be about $3 \%$ a year, but it is probably much lower. That part of the guidelines is based more on eminence than evidence; it would be terrible if attempts to treat patients who might benefit distracted us from treating those who we know will benefit.

David Lewis General practitioner

Vauxhall Primary Health Care, Liverpool L5 8XR

1 Freemantle N, Barbour R, Johnson R, Marchment M, Kennedy A. The use of statins: a case of misleading priorities? BMJ 1997;315:826-8. (4 October.)

2 Haq IU, Jackson PR, Yeo WW, Ramsay LE. Sheffield risk and treatment table for cholesterol lowering for primary prevention of coronary heart disease. Lancel 1995;346:1467-71.

3 UK-TIA Study Group. United Kingdom transient ischaemic attack (UK-TM) aspirin trial: interim results. BMJ 1988;296:316-20.

4 Heyman A, Wilkinson WE, Hurwitz BJ, Haynes CS, Utley $\mathrm{CM}$, Rosati RA, et al. Risk of ischaemic heart disease in CM, Rosati RA, et al. Risk of ischaemic heart
patients with TIA. Neurology 1984;34:626-30.

5 Criqui MH, Langer RD, Fronek A, Feigelson HS, Klaube MR, McCann TJ, et al. Mortality over a period of 10 years $\mathrm{MR}, \mathrm{McCann} \mathrm{T}$, et al. Mortality over a period of 10 years
in patients with peripheral vascular disease. $N$ Engl J Med 1992;326:381-6.

\section{Evidence on effectiveness is stronger for} statins than for other treatments

EDITOR-Freemantle et al identify the main problem with implementing the new evidence for statins - that it will entail treating many people with relatively expensive drugs. ${ }^{1}$ They are wrong, however, to attack the Standing Medical Advisory Committee's guidance and the evidence that underpins it.

The body of evidence on effectiveness, individual benefit (number needed to treat), ${ }^{2}$ cost effectiveness, ${ }^{3}$ methods of targeting treatment, ${ }^{24}$ and the population and cost implications of treatment policies ${ }^{23}$ is arguably stronger for statins than for any treatment in wide use. The benefit from treatment (a one third reduction in major coronary events) could hardly be clearer. The reduction in relative risk is constant above a low density lipoprotein cholesterol concentration of $3.2 \mathrm{mmol} / \mathrm{l}$. Absolute benefit is therefore determined by absolute risk, and the assumptions underpinning primary prevention are sound.

Freemantle et al seriously understate benefit by citing the number needed to treat to avoid one death, which was not the principal end point in the trials. The number needed to treat to avoid major coronary heart disease events (coronary death, nonfatal myocardial infarction) is much smaller. The number needed to treat for five years at a risk of a coronary heart disease event of 
$3 \%$ per year is 20 for major coronary heart disease events, ${ }^{2}$ not the 55 cited, even when benefits such as significant reductions in stroke and bypass grafts are excluded. The cost effectiveness of statin treatment at different levels of risk has been examined; at a risk of $3 \%$ per year it is comparable to or better than that for many treatments in common use. ${ }^{3}$ The authors question the validity of the Framingham risk function and Sheffield tables for predicting risk of coronary heart disease. However, the Framingham risk function predicted average risk accurately in the placebo group in WOSCOPS (west of Scotland coronary prevention study) and gives risk estimates in individuals that agree with those derived from northern European populations. ${ }^{5}$

The authors consider that implementation of the Standing Medical Advisory Committee's guidance is "probably unachievable." Are we really to accept that the health service of a civilised society cannot deliver treatment that is so effective and acceptably cost effective? The phrase "enthusiasts for cholesterol lowering drugs" is out of place: healthcare professionals who are not enthused by the evidence from the statin trials should consider some other career. General practitioners are not overwhelmed and doing little. Many are impressed by the quality of the evidence and already implementing it. The guidance provides them with logical priorities when doing so.

E J Wallis Research assistant

L E Ramsay Professor

W W Yeo Senior lecture

P R Jackson Reader

Section of Clinical Pharmacology and

Therapeutics, Department of Medicine and

Pharmacology, Royal Hallamshire Hospital, Sheffield S10 2JF

M Pickin MRC research fellow in public health medicine

Medical Care Research Unit, Sheffield Centre for Health and Related Research,Sheffield S1 4DA

I U Haq Specialist registrar

Department of Cardiology, Northern Genera

Hospital, Sheffield S5 7AU

1 Freemantle N, Barbour R, Johnson R, Marchment M, Kennedy A. The use of statins: a case of misleading priorities? BMJ 1997;315:826-8. (4 October.)

2 Haq IU, Ramsay LE, Pickin DM, Yeo WW, Jackson PR, Payne JN. Lipid-lowering for prevention of coronary heart disease: what policy now? Clin Sci 1996;91:399-413.

3 Working Group on Acute Purchasing. Statin therapy/HMC coA reductase inhibitor treatment in the prevention of coromary $c o A$ reductase inhibitor treatment in the prevention of coromary
heart disease. Sheffield: Trent Institute for Health Services Research, University of Sheffield, 1996. (Guidance note for Research, University
purchasers $96 / 04$.)

purchasers 96/04.)
4 Ramsay LE, Haq IU, Jackson PR, Yeo WW, Pickin DM, Payne JN. Targeting lipid-lowering drug therapy for primary prevention of coronary disease: an updated Sheffield table. Lancet 1996;348:387-8.

5 Haq IU, Yeo WW, Jackson PR, Ramsay LE. A comparison of methods for predicting coronary risk in men free of vascular disease. Heart 1997;77(suppl 1):10.

\section{Sheffield tables have shortcomings}

Editor-Since their publication the Sheffield tables ${ }^{1}$ have been distributed to the medical profession by both the Consumers Association $^{2}$ and, more recently, the Standing Medical Advisory Committee. ${ }^{3}$ Although we agree with the advisory committee that calculation of the absolute risk of coronary heart disease is an essential prerequisite for decisions on primary pre- vention, we have misgivings about the use of the Sheffield tables for this purpose.

The tables are based on data correlating the absolute risk of coronary heart disease with the risk factor status of individuals in the Framingham study; however, they have been simplified by excluding variation in high density lipoprotein cholesterol from the analysis and dichotomising blood pressure into normotensive or hypertensive. We believe that these simplifications could lead to major errors in the estimate of absolute risk. This is of particular concern when estimating risk in patients with non-insulin dependent diabetes, whose high density lipoprotein cholesterol is often low.

Another concern is that the tables militate against the measurement of serum cholesterol in younger people without nonlipid risk factors, 1 in 500 of whom have familial hypercholesterolaemia, which is associated with a nearly 50-fold increase in the risk of death from coronary heart disease between the ages of 20 and 39 (A Neil, personal communication). In contrast they promote treatment with lipid lowering drugs for elderly people despite the paucity of evidence of benefit from such intervention in asymptomatic people aged over 65 . Thus 70 year old male smokers are considered eligible for statin treatment if their serum cholesterol is $5.5 \mathrm{mmol} / \mathrm{l}$, which seems inappropriate on both scientific and financial grounds.

We consider that calculation of absolute risk is best done by using the full Framingham risk score,${ }^{4}$ which is available in a mmol/l version on a computer disk, free of charge. We also advocate calculating the relative risk of coronary heart disease as well as the absolute risk and suggest that below the age of 65 a relative risk of $\geqslant 4$ may require action whereas above that age the value should be $\geqslant 2$ before treatment is considered, whatever the absolute risk. As regards which level of absolute risk should determine eligibility for treatment, we tend to favour a risk of $20 \%$ over 10 years, as advocated by the European Societies of Cardiology and Hypertension and the European Atherosclerosis Society, ${ }^{5}$ rather than the $30 \%$ risk advocated by the Standing Medical Advisory Committee. ${ }^{3}$ The latter value can be justified only on the grounds of treatment costs, which will decrease considerably when statins can be manufactured generically.

John Betteridge Chairman, British Hyperlipidaemia Association

Department of Medicine, Middlesex Hospital, London W1N 8AA

James Shepherd Past chairman, European

Atherosclerosis Society

Department of Pathological Biochemistry, Royal Infirmary, Glasgow G4 0SF

Gilbert Thompson Chairman, British Atherosclerosis Society

MRC Lipoprotein Team, Hammersmith Hospital, London W12 0HS

1 Haq IQ, Jackson PR, Yeo WW, Ramsay LE. Sheffield risk and treatment table for cholesterol lowering for primary prevention of coronary heart disease. Lancet 1995;346:1467-71.
2 Management of hyperlipidaemia. Drug Ther Bull 1996;34(suppl):89-93.

NHS Fxecutive SMAC statement on use of statins. Wetherby, West Yorkshire: Department of Health, 1997. (Executive letter EL(97)41.)

4 Anderson KM, Wilson PWF, Odell PM, Kannel WB. An updated coronary risk profile. A statement for health proupdated coronary risk profile. A state

5 Pyörälä K, de Backer G, Graham I, Poole-Wilson P, Wood Pyörälä K, de Backer G, Graham I, Poole-Wilson P, Wood
D on behalf of the task force. Prevention of coronary hear disease in clinical practice: recommendations of the Task Force of the European Society of Cardiology, European Atherosclerosis Society, and European Society of Hypertension. Eur Heart J 1994;15:1300-31.

\section{Cost effectiveness was studied in $4 \mathrm{~S}$ study}

Editor-Freemantle et al criticise the recommendations from the Standing Medical Advisory Committee on the use of statins to prevent coronary artery disease because due attention is not paid to the link between cost and benefits. ${ }^{1}$ Some of their statements concerning the Scandinavian simvastatin survival study (4S) are biased and require comment.

The $4 \mathrm{~S}$ had sufficient power to avoid bias in the final estimate of efficacy. ${ }^{2}$ The data and safety monitoring committee recommended that the trial be stopped because of overwhelming benefit in favour of the active treatment group when the number of deaths was 438 , close to the 440 deaths expected for the completed trial. The narrow confidence intervals indicated a high validity in the result. Thus the statement that the early ending of the trial was data driven and so may have overestimated the effects is unreasonable.

The authors' table showing numbers of patients who died or had myocardial infarction gives only the number admitted to hospital with confirmed infarction; patients with probable myocardial infarction, silent myocardial infarction, and infarction associated with an intervention are omitted. For patients and for economic evaluation, any major coronary event leading to admission will be equally important. In $4 \mathrm{~S}$ the reduction in absolute risk for such events with simvastatin is $6.2 \%$, or if all coronary events are considered $6.7 \%$, not $4.8 \%$. The table therefore underestimates the full impact of the disease and the benefit of treatment. The benefits continue to accrue the longer the treatment is given, and the number of lives saved over five years is likely to underestimate the long term benefit of this treatment in clinical practice.

The reduction in absolute risk depends on risk, and patients whose low density lipoprotein cholesterol concentrations are low have less benefit in absolute terms than patients with high concentrations. Freemantle et al therefore demand evidence on benefits and costs for these groups of patients. Three reports on cost minimisation and cost effectiveness have been published from $4 \mathrm{~S}^{3-5}$ showing that simvastatin is highly cost effective by reducing days in hospital and need for revascularisation, for all cholesterol concentrations studied. The cost effectiveness of simvastatin compares with that of bypass surgery for main stem and three vessel disease but is far greater than that of bypass surgery for two vessel disease. If indirect costs (for example, greater productivity 
because the patients stays healthy longer) is included in the analysis the treatment is cost saving in younger patients. ${ }^{5}$

For patients with the $4 \mathrm{~S}$ criteria, information on cost effectiveness exists and the data are more encouraging than the editorial suggests.

John Kjekshus Chairman of steering committee for $4 S$ Department of Medicine B, University of Oslo, Rikshospitalet, Oslo, Norway

Terje R Pedersen Coordinator for $4 S$

Department of Medicine, University of Oslo, Aker Hospital, Oslo

1 Freemantle N, Barbour R, Johnson R, Marchment M Kennedy A. The use of statins: a case of misleading priorities? BMJ 1997;315:826-8. (4 October.)

2 Scandinavian Simvastatin Survival Study Group. Randomised trial of cholesterol lowering in 4444 patients with coronary heart disease: the Scandinavian simvastatin survival study (4S). Lancet 1994;344:1383-9.

3 Pedersen TR, Kjekshus JK, Berg K, Olsson AG, Wilhelmsen $\mathrm{L}$, Wedel $\mathrm{H}$, et al Cholesterol lowering and the use of the health care resources: results of the Scandthe use of the health care resources. results of the Scandinavian simvastatin 4 Jonsson B, Johannesson M, Kjekshus J, Olsson AG, Pedersen TR, Wedel H. Cost-effectiveness of cholesterol lowering: results from the Scandinavian simvastatin survival study (4S). Eur Heart J 1996;17:1001-7.

5 Johannesson M, Jonsson B, Kjekshus J, Olsson AG, Pedersen TR, Wedel H. Cost-effectiveness of simvastatin treatment to lower cholesterol levels in patients with coronary heart disease. N Engl J Med 1997;336:332-6.

\section{Standing Medical Advisory Committee should reconsider advice to use Sheffield risk table}

EDITOR-The Standing Medical Advisory Committee's guidelines for primary and secondary prevention of vascular disease and treatment of hyperlipidaemia ${ }^{1}$ recommend that primary prevention should be governed by the Sheffield risk table propounded by Ramsey et al. ${ }^{2}$ As clinicians running many of the United Kingdom's specialist cardiovascular or lipid clinics, we are pleased that the Department of Health has finally accepted the overwhelming evidence that cholesterol lowering is essential. We wish, however, to express our concern about the guidelines:

The Sheffield risk table is based on an arbitrarily high risk of coronary heart disease of 30\% over 10 years; this is contrary to established international opinion, which sets a threshold of risk of 15-20\% (European Society of Cardiology/European Atherosclerosis Society /European Society of Hypertension; American Heart Association; New Zealand Medical Society). Additionally, the table dismisses many important risk factors and their varying severity by relegating them to footnotes. ${ }^{3}$ These risk factors include the high frequency of familial hyperlipidaemias (1 in 200 to 1 in 500) and the effect of family history; the influence of ethnic origin, particularly in Asians; and the effect of high density lipoprotein and triglyceride concentrations. The table thus ignores the poor prognoses associated with these risk factors and the need for early treatment in patients with them.

Unfortunately, doctors will probably use the table to avoid cholesterol testing in younger patients without noting the "small print." This will ensure that primary prevention is not offered to patients who would benefit. Such patients would only receive secondary prevention, after irreparable damage had been allowed to occur. Secondary prevention can be defined as "primary prevention that has occurred too late." Thus use of the Sheffield risk table could be considered to be state sponsored negligent practice.

We urge the Standing Medical Advisory Committee to reconsider its advice to use the Sheffield risk table. We urge clinicians to continue to use other, more appropriate and more widely recognised, guidelines on lipid treatment, such as those published by the British Hyperlipidaemia Association ${ }^{4}$ or the European societies. ${ }^{5}$

Signed by 103 professors, consultants, and specialists in preventive cardiology, chemical pathology, metabolism and lipids, clinical pharmacology, epidemiology, and public health from England, Wales, and Northern Ireland

Correspondence to $\mathrm{Dr} \mathrm{T}$ M Reynolds, Clinical Chemistry Department, Queen's Hospital, Burton upon Trent, Staffordshire DE13 ORB

1 NHS Executive. SMAC statement on use of statins. Wetherby, West Yorkshire: Department of Health, 1997. (Executive West Yorkshire:

2 Ramsey L, Haq I, Jackson R, Yeo W. The Sheffield table for primary prevention of coronary heart disease. Lancet 1996;348:387-8, 1251-2

3 Tunstall-Pedoe H, Woodward M, Tavendale R, A'Brook R, McCluskey M. Comparison of the prediction by 27 different factors of coronary heart disease and death in men and women of the Scottish heart study: cohort study. BMJ 1997;315:722-9. (20 September)

4 Betteridge D, Dodson P, Durrington P, Hughes E, Laker M, Nicholls D, et al. Management of hyperlipidaemia: videlines of the British Hyperlipidaemia Association. guidelines of the British Hyperit
Postgrad Med J 1993;69:359-69.

Pyorala K, De 1993,69.559-69. P on behalf of the task force. Prevention of coronary heart $\mathrm{D}$ on behalf of the task force. Prevention of coronary heart disease in clinical practice: recommendations of the task force of the European Society of Cardiology, European
Atherosclerosis Society and European Society of Hypertension. Eur Heart J 1994;15:1300-31.

\section{NHS bonds could be alternative to private finance initiative for NHS}

EDITOR-Concern is growing as more detail is revealed about the private finance initiative in the NHS. ${ }^{1}$ Negotiations over the initiative are conducted under terms of commercial confidentiality. Health professionals and the public are effectively shut out as commercial imperative takes precedence over social purpose.

The private finance initiative is a costly option. Participating consortiums expect an annual return on investment of $15 \%$ or more, to be met by taxpayers (or charges on patients) locked in for 30-60 years. Many schemes for which the private finance initiative will be used require large reductions in hospital beds to make them commercially viable, when existing bed supply in the NHS is supersaturated. Recent legislation could permit extension of the initiative to the provision of bedside services. Will "hard choices" drive us down that road, however unwillingly? Acquisitive buyouts of consortiums participating in the initiative could even see the NHS providing income for foreign speculators. No longer standing for "private finance initiative," PFI comes to stand for "profiting from illness."
Many health professionals mistrust the private finance initiative in the NHS but see no other way to raise capital for hospital or other schemes. We propose a better and less costly alternative. The issue of government backed NHS bonds would present an ethically highly acceptable opportunity to large institutional investors such as pension funds and insurance companies with a stake in sound social infrastructure and would attract private individuals seeking safe and worthwhile investment. NHS bonds would command a much lower rate of return for shorter periods than would the private finance initiative- a far better bargain for the taxpayer. Of no less importance, healthcare policy would remain firmly in public hands.

Objections that NHS bonds would contribute to the public sector borrowing requirement and offend against the "Maastricht criteria" for a single European currency are questionable. Borrowing for social investment can be excluded from the ratio of general government debt to gross domestic product (the Maastricht indicator of the sustainability of government $\operatorname{debt}^{2}$ ), and the public acquires a capital asset. Alternatively, NHS bonds could be issued locally, regionally, or through a public corporation.

The drawbacks and dangers of the private finance initiative to the NHS are only too clear. Until the Treasury finds more money, NHS bonds are surely a more prudent alternative if we wish to retain the NHS safely in our hands.

Harry Keen President, NHS Support Federation Apartment 12, Provost Court, 3-6 Eton Road, London NW3 4SR

Peter Fisher Chairman, NHS Consultants'Association Hill House Great Bourton, Banbury, Oxfordshire OX17 1QH

Peter Draper Secretary, Health Policy Network 45 Fortis Green Road, London N10 3HP

Pollock AM, Dunnigan M, Gaffney D, Macfarlane A, Majeed A on behalf of the NHS Consultants' Association, Radical Statistics Health Group, and the NHS Support Federation. What happens when the private sector plans hospital services for the NHS: three case studies under the private finance initiative. BMJ 1997;314:1266-71.

2 Radcliffe R. Accounting for investment. New Economy 1996;3:164-8

\section{Guidelines are needed for evaluations that use cluster approach}

EDITOR-The recent report of the success of feedback to general practitioners about their prescribing practices $^{1}$ contains important messages both about the potential for major public health benefits resulting from changing doctors' behaviour and about alternative methods for evaluating heath education interventions. ${ }^{2}$ In this example, taking the general practice as the unit of randomisation rather than the individual patients with heart disease was entirely appropriate.

It is important, however, that cluster randomised trials are presented in the same way as randomised controlled trials that randomise individuals to treatments-that is, guided by the CONSORT statement. ${ }^{3}$ On this basis, power calculations would have 
been shown to enable readers to identify whether a sample size of 28 (practices) was appropriate. In the particular context of cluster randomisation, extra information that might be helpful would be the size of these practices in terms of the number of general practitioners working in them (which is given, but not by allocated groups); the overall patient population per practice; the number of patients with the target disease; and current prescribing practices (which are helpfully shown in the figure). This information would allow readers to assure themselves that the practices in the two trial arms were similar at the outset and would also have been helpful if the investigators had decided to use a paired design. Depending on the variability identified, this might have led to an increase in the power of the trial, as suggested by Shipley et $\mathrm{al}^{4}$ in a paper based on an earlier matched pairs trial.

Increasing numbers of evaluations are likely to use this cluster approach in the future. Specific guidelines for their presentation would be appreciated.

Diana Elbourne Senior lecturer

Department of Epidemiology and Population

Health, Medical Statistics Unit, London School of

Hygiene and Tropical Medicine, London

WC1E 7HT

1 McCartney P, Macdowall W, Thorogood M. A randomised controlled trial of feedback to general practitioners of their prophylactic aspirin prescribing. BMJ 1997;315:35-6. (5 July.)

2 Donner A, Klar N. Methods for comparing event rates in intervention studies when the unit of allocation is a cluster. Am J Epidemiol 1994:140:279-89.

3 B et al. Improving the quality of reporting of randomize controlled trials. The CONSORT statement. JAMA

4 Shipley MJ, Smith PG, Dramaix M. Calculation of power for matched pair studies when randomisation is by group. Int J Epidemiol 1989;18:457-61.

5 Grant AM, Elbourne DR, Valentin L, Alexander S. Routine formal fetal movement counting and risk of antepartum late death in normally-formed singletons. Lancet 1989;ii:345-9.

\section{Evidence based advertising?}

\section{Advertisement for nifedipine does not mention admitted shortcomings of study}

EDITOR-I am concerned about an advertisement for nifedipine (Adalat) that appeared in the $B M J$ in the issue of 12 April: referring to the STONE study, it says "This prospective placebo-controlled clinical intervention trial has demonstrated for the first time a significant reduction in severe clinical outcomes with the dihydropyridine nifedipine." This text is the last sentence of the discussion in an article in the Journal of Hypertension. ${ }^{1}$

The shortcomings of the study are mentioned by the authors themselves. At the end of their introduction they state: "It is our belief, however, that within the stated restrictions the study design and execution warrant publication of the results in an international journal." At the start of the discussion they again mention the shortcomings: "Because of its unorthodox design (single-blinded sequential assignment with transfer of severely hypertensive subjects from placebo to active treatment group), we decided to approach the data via different types of analysis to limit overinterpretation bias."

Readers of the advertisement, however, are not aware of the shortcomings on which it is based. They will thus suppose that it concerns a prominent clinical study which may have consequences in clinical practice-in this case, the adjustment of treatment in patients with moderate hypertension. The $B M J$ strongly advocates controlled clinical trials and is dismissive of attempts to use statistical fireworks to overcome a study's shortcomings. I presume that it would agree that, according to its own criteria, nothing is shown by the publication cited in the advertisement.

The BMJ should make clear to its readers that, currently, scientifically founded data on the treatment of hypertension are available only for thiazide diuretics and $\beta$ lytics and that the effects of using calcium entry blockers are still unknown. In the editor's footnote to recent letters about advertisements in the $B M J$ the editor wrote that the journal rarely rejects advertising material on the grounds of unsubstantiated or misleading claims. ${ }^{2}$ I think that the advertising policy should be changed. The references that are used in advertisements should be checked for their scientific relevance.

Luc Blondeel General practitioner

Projekt Farmaka, Jozef Vervaenestraat 14, 9050

Ghent, Belgium

1 Gong L, Zhang W, Zhu Y, Zhu J, et al. Shanghai trial of nifedipine in the elderly. J Hypertens 1996;14:1237-45. 2 Advertisements for donepezil (Aricept) in the BMJ [letters]. BMJ 1997;314:1555-6. (24 May.)

\section{Reply from manufacturer}

EDiToR-Blondeel's concerns about the advertisement for nifedipine raise several issues. The advertisement was placed to highlight the first study to be published in a peer reviewed journal with an international reputation (the Journal of Hypertension) that describes the first intervention trial in hypertensive patients to show that a dihydropyridine calcium channel blocker (nifedipine) may confer long term benefits in terms of morbidity and mortality. ${ }^{1}$ The findings of this study have recently been supported by the results of the systolic hypertension in Europe trial for the dihydropyridine nitrendipine. ${ }^{2}$

These studies give the first indication that, in common with thiazide diuretics and $\beta$ blockers, ${ }^{3}$ dihydropyridine calcium antagonists also confer long term benefits for hypertensive patients. There are further ongoing prospective outcome studies in hypertension, including one reported by Brown et al, which will provide more evidence of the influence that this class of compounds has on outcomes. ${ }^{4}$

As with all advertisements in medical journals, it is the responsibility of pharmaceutical companies to comply with the Medicines Act and the code of practice of the Association of the Pharmaceutical Industry. Bayer takes these responsibilities very seriously, and the code of practice is rigorously applied to all such advertisements.

Nevertheless, it is important that ethical pharmaceutical companies should communicate important developments in medical science to the medical profession. The medical information department at Bayer will be pleased to supply scientific and technical information relating to such developments to any member of the profession in Britain so that individual doctors can assess such information and formulate their own prescribing policies.

Graham Leighton Head of medical affairs

Michael E Telford Medical affairs physician

Bayer, Pharmaceutical Division, Newbury, Berkshire RG14 1JA

1 Gong L, Zhang W, Zhu Y, Zhu J, et al. Shanghai trial of nifedipine in the elderly (STONE). J Hypertens 1996; 14:1237-45.

2 Staessen JA, Fagard R, Thijs L, Celis H, Arabidze GG, BirkStaessen JA, Fagard R, Thijs L, Celis H, Arabidze GG, Birk-
enhäger WH, et al for the Systolic Hypertension in Europe enhäger WH, et al for the Systolic Hypertension in Europe
(Syst-Eur) Trial Investigators. Randomised double-blind comparison of placebo and active treatment for older comparison of placebo and active treatment for older
patients with isolated systolic hypertension. Lancet 997;350:757-76

Medical Research Council Working Party. MRC trial of treatment of mild hypertension: principal results. BMJ $1985 ; 291: 97-104$

4 Brown M J, Castaigne A, Ruilape LM, Mancia G, Rosentha T, de Leeuw PW, et al. INSIGHT: international nifedipine GITS study intervention as a goal in hypertension treatment. J Hum Hypertens 1996;10(suppl 3):S157-60.

\section{Reply from author of STONE study}

EDITOR-I have been sent a copy of Blondeel's letter about the advertisement for nifedipine (Adalat). He comments on the STONE study and Bayer's advertisement for the drug, which has the heading "Research for the future: STONE study." As the senior author of the study and the author of the sentence depicted in the advertisement and quoted in Blondeel's letter, I would like to make several comments.

I appreciate that Blondeel carefully read the report of the STONE study and noted shortcomings, which my colleagues and I mentioned in the paper. It is surprising that Blondeel has picked up only the shortcomings, which we discussed openly to make readers aware of the study's entire content. Unfortunately, Blondeel has missed all the positive points, which we also underlined in a balanced way. The STONE study is the first prospective controlled trial that tested this new type of drug against placebo; it concluded in a strong, unambiguous way that treatment with nifedipine is better than placebo, protecting against stroke and overall cardiovascular events.

The STONE study is not weaker than the original Veterans Administration study; it is similar in design and shortcomingswhich we discussed. The Veterans Administration study was a landmark proving that hypertension treatment is worth while. We believe that the STONE study is also a landmark study giving doctors the opportunity to rely on newer classes of drug. We scrupulously and openly discussed in our paper the study's strengths and weaknesses; this is 
usually not done, and frequently only other analyses review weaknesses.

Naturally, we must await the results of further studies to confirm our findings. From what was presented at the last European meeting on hypertension, it seems that studies such as the systolic hypertension in China and systolic hypertension in Europe studies will have the power to address the question of whether the STONE study was the first to show that nifedipine is a proved agent able to reduce morbid events. Despite Blondeel's comments, I believe that openness and criticism by authors should be kept as a standard, should not be used to diminish the value of the data, and serve to facilitate proper weighing of the evidence.

Pavel Hamet* Director of research

Centre Hospitalier de l'Université de Montréal, Pavillon Hôtel-Dieu, Montreal, Quebec, Canada H2W 1 T8

*Pavel Hamet is supported by grants from Bayer, Merck Frosst, and Pfizer Canada and is a consultant for Servier.

1 Effects of treatment on morbidity in hypertension. II. Results in patients with diastolic blood pressure averaging 90 through 114 mm Hg. JAMA 1970;213:1143-52.

\section{Only two fifths of advertisements cited} published, peer reviewed references

EDITOR-We were interested in the editor's footnote to the letters about advertisements in the $B M J$; he wrote that the $B M J$ rarely rejects advertising material on the grounds of unsubstantiated or misleading claims. ${ }^{1} \mathrm{We}$ have examined the extent to which recent pharmaceutical advertising in the $B M J$ quoted published evidence and therefore gave clinicians the opportunity to assess advertisers' claims.

We examined all advertisements for pharmaceutical products in 10 consecutive issues of the BMJ. For each advertisement we recorded whether it carried references, how many it cited, and how many were to published material. We determined whether the published material had been peer reviewed by using Ulrich's Directory of Refereed Serials and the Serials Directory 1995. Publications not appearing in the appropriate sections of either were considered not to have been peer reviewed. For references available in our medical school library we ascertained whether the material supported the advertisement's assertions.

In the issues of the $B M J$ from 1 March to 3 May 1997 there were 46 different advertisements for 40 pharmaceutical products, which cited 102 references (median 1 (range $0-8)$ ). Fifteen of the advertisements cited no references, seven referred to unpublished information only, 15 referred to published material only, and nine referred to both.

The table shows the types of references cited. Only two fifths of the advertisements (19) cited any published, peer reviewed references. Of the 55 references to peer reviewed journals, 13 were to abstracts or sponsored symposiums published in the journal (four) or a journal supplement (nine). Journal supplements have been shown to carry articles inferior in quality to
Types of references in 46 different product advertisements. Figures are numbers of references

\begin{tabular}{lr} 
& No \\
\hline Unpublished material: & \\
\hline Company data* & 20 \\
\hline Conference presentations and abstracts & 11 \\
\hline Total & 31 \\
\hline Published material: & 55 \\
\hline Peer reviewed journal: & 39 \\
\hline $\begin{array}{l}\text { Original research or review article in peer } \\
\text { reviewed journal }\end{array}$ & 13 \\
\hline \multicolumn{2}{l}{ Abstracts and presentations } \\
\hline Editorials or letters in peer reviewed journals \\
\hline Other material in public domain & 3 \\
\hline Total & 16 \\
\hline Overall total & 102
\end{tabular}

*Either data on company file or product information.

those published in the parent journal. ${ }^{2}$ Thirty four references were to peer reviewed papers available in our medical school library. Although all of these could be used to support assertions made in the advertisements, they sometimes entailed selective reading of study results or were references to a study with methodological problems or a statement concerning the disease rather than the product.

The main purpose of our study was to ascertain whether interested clinicians could obtain the evidence used to advertise a product in order to judge its worth for themselves. Given that doctors are encouraged to practise evidence based medicine ${ }^{3}$ and that advertising is said to be effective at increasing sales for most products, ${ }^{4}$ it is worrying that this was possible for only a third of the advertisements and only two fifths of the cited references.

Jennifer Mindell Senior registrar in public health medicine

Trudi Kemp Lecturer in public health medicine Department of Public Health Medicine and Epidemiology, University Hospital, Queen's Medical Centre, Nottingham NG7 2UH

1 Advertisements for donepezil (Aricept) in the BMJ [letters]. BMJ 1997;314:1555-6. (24 Mav.)

2 Rochon PA, Gurwitz JH, Cheung M, Hayes JA, Chalmers Rochon PA, Gurwitz JH, Cheung M, Hayes JA, Chalmers
TC. Evaluating the quality of articles published in journal supplements compared with the quality of those published in the parent journal. JAMA 1994;272:108-13.

3 NHS Management Executive. Improving clinical effectiveness. Leeds: Department of Health, 1993. (EL(93) 115.) 4 Foote E. Advertising and tobacco. JAMA 1981;246:1667-8.

\section{"Cash for questions" is not limited to MPs}

EDiToR-The 1 November issue of the Clinical Research edition contained a looseleaf copy of a reader survey. The questions were clearly designed to make the journal more useful to pharmaceutical companies and not, as the preamble suggested, the journal's readers. I give here some of the questions asked, with my interpretation in italics.

1 What type of organisation do you work in?

Which types of drug should we advertise in the BMJ? Hospital based products or drugs to be used in the community?

2 What is your specialty?

Which particular products might it be more lucrative for pharmaceutical companies to advertise in the BMJ?
3 When do you read the $B M]$ ?

What is the optimum frequency at which to advertise a product in the BMJ?

4 With an average issue of the $B M J$, approximately how much time do you spend reading the following sections [sections listed here]?

In which particular section of the BMJ is it best to place an advertisement for a product?

5 How much time do you spend reading the following weekly medical journals [various journals listed]?

Would it be better to advertise our [the pharmaceutical company's] product in another journal?

6 How many conferences/courses/ seminars do you attend in a year?

Should we [the pharmaceutical company] spend more time and effort advertising our products at conferences, courses, or seminars?

7 How many external meetings, organised by pharmaceutical manufacturers, have you attended during the last six months?

Should we [the pharmaceutical company] bother organising our own external meetings?

8 At what point after launch do you first administer a new drug?

What is the best time to start "the hard sell"?

I hope that my point is clear. This questionnaire was nothing more than thinly veiled market research on behalf of the pharmaceutical companies which presumably pay large amounts of money to have their products advertised in the $B M J$. If the journal really wants to be more useful to its readers perhaps it should carry only advertisements for drugs that are backed by sound scientific evidence of their worth over other comparable products; or publish such research before publishing any advertisements for the product. The journal should exist to educate and stimulate its readers, not use them to help pharmaceutical companies.

Steven Crane Specialist registrar in accident and emergency medicine

Leeds General Infirmary, Leeds LS1 3EX

Half of drug advertisements in $B M J$ over six months cited no supporting evidence

EDITOR-Pharmaceutical companies try to make drug advertisements and promotional literature salient, ubiquitous, and memorable. Disquiet has recently been expressed about the intrusiveness of advertising and the quality of evidence presented in it. ${ }^{1}$ The editor has stated that it is practice in the $B M J$ for the editorial team to review drug advertisements before publication. ${ }^{1}$ Advertisements may be rejected if deemed offensive but are rarely rejected because of the quality of supporting evidence. Evidence based medicine relies on a clinician having access to a database of evidence and the strategies to search, appraise, and update such evidence. ${ }^{2}$ For advertisements in peer reviewed journals, is it not reasonable to expect that pharmaceutical companies apply the same rigour to their advertising copy as clinicians are expected to apply to their clinical publications? 
Various types of evidence quoted in drug advertisements. Figures are number of references (refs) in advertisements and number of advertisements (adverts)

\begin{tabular}{|c|c|c|c|c|c|c|c|c|c|c|c|}
\hline \multirow[b]{2}{*}{ Type of drugs } & \multirow[b]{2}{*}{ n } & \multirow[b]{2}{*}{ Adverts } & \multicolumn{2}{|c|}{$\begin{array}{l}\text { Meta-analyses } \\
\text { and systematic } \\
\text { reviews }\end{array}$} & \multicolumn{2}{|c|}{$\begin{array}{l}\text { Randomised } \\
\text { controlled } \\
\text { trials }\end{array}$} & \multicolumn{2}{|c|}{$\begin{array}{l}\text { Cohort, } \\
\text { case-control and } \\
\text { cross sectional } \\
\text { studies, case } \\
\text { reports, and } \\
\text { non-systematic } \\
\text { reviews }\end{array}$} & \multicolumn{2}{|c|}{$\begin{array}{l}\text { Conference } \\
\text { abstracts, data } \\
\text { on file, and } \\
\text { incorrect } \\
\text { references }\end{array}$} & \multirow{2}{*}{$\begin{array}{c}\text { No } \\
\text { supporting } \\
\text { evidence } \\
\text { provided }\end{array}$} \\
\hline & & & Refs & Adverts & Refs & Adverts & Refs & Adverts & Refs & Adverts & \\
\hline Antibiotics & 5 & 7 & 0 & 0 & 5 & 2 & 7 & 1 & 10 & 2 & 2 \\
\hline Cardiovascular & 13 & 15 & 1 & 1 & 7 & 5 & 8 & 1 & 0 & 0 & 8 \\
\hline Gastrointestinal & 5 & 8 & 0 & 0 & 2 & 1 & 3 & 0 & 1 & 1 & 6 \\
\hline Oncology & 6 & 6 & 0 & 0 & 3 & 3 & 5 & 1 & 1 & 0 & 2 \\
\hline Neurological & 4 & 5 & 0 & 0 & 3 & 1 & 3 & 0 & 5 & 1 & 3 \\
\hline Psychiatric & 8 & 12 & 1 & 1 & 13 & 4 & 14 & 2 & 14 & 2 & 3 \\
\hline Respiratory & 6 & 12 & 0 & 0 & 5 & 2 & 0 & 0 & 6 & 1 & 9 \\
\hline Urological & 3 & 3 & 0 & 0 & 0 & 0 & 2 & 1 & 0 & 0 & 2 \\
\hline Other & 13 & 13 & 0 & 0 & 3 & 2 & 4 & 2 & 13 & 4 & 5 \\
\hline Total & 63 & 81 & 2 & 2 & 41 & 20 & 46 & 8 & 50 & 11 & 40 \\
\hline
\end{tabular}

We identified all advertisements promoting drugs that were published in the $B M J$ over six months (Jul-Dec 1996). Altogether we identified 63 different drugs in 81 different advertisements. Where the same drug was advertised in different advertisements, we identified all versions of the advertisement separately. We obtained original papers or their abstracts for all references in the public domain and rated the advertisements in terms of the quality of evidence as relating to study design, using a standard "hierarchy of evidence." ${ }^{3}$ We did not obtain data held on file by pharmaceutical companies or presented solely at conferences as they are not widely available for literature searching. The table shows the results.

Only two meta-analyses and 41 randomised controlled trials were cited, several in the same advertisements. Only a quarter (22) of the advertisements provided this high level of evidence. In contrast, half (40) of the advertisements cited no supporting evidence at all. Two advertisements provided no evidence for claims or provided only references to data held on file or published as conference abstracts. No attempt was made to identify whether papers were sponsored by the pharmaceutical companies concerned, which raises issues of conflict of interest.

Pharmaceutical companies clearly believe that advertising is effective. Whether this presumption is correct or not, drug advertisements are one source of information for clinicians. We believe that peer reviewed journals and the pharmaceutical industry should adopt more rigorous approaches to promote truly evidence based advertising. In particular, supporting evidence should be of high quality and accessible to readers so that they can review it and make their own judgments about the content of advertisements.

Siobhan Smart Senior registrar in child and adolescent psychiatry

Chris Williams Senior lecturer in psychiatry

St James's University Hospital, Leeds LS9 7TF

1 Advertisements for donepezil (Aricept) [letters]. BMJ 1997;314:1555-6. (24 May.)

2 Sackett DL, Rosenberg WMC, Gray JAM, Haynes RB, Richardson WS. Evidence based medicine: what it is and what it isn't. BMJ 1996;312:71-2.
3 Greenhalgh T. Assessing the methodological quality of published papers. BMJ 1997;315:305-8.

* The editor comments on these letters in his footnote to the cluster below (p 1625).

\section{Advertisements for donepezil}

\section{More convincing evidence of efficacy} needs to be cited

EDITOR-The inside back cover of the $B M J$ seems to have become a regular slot for an advertisement for the anti-dementia drug donepezil. The caption "Mum has Alzheimer's but she knew I was calling today" is a powerful claim for efficacy in a condition currently believed to be incurable and relentlessly progressive.

The three references cited in the advertisement to support this claim include two to data on file and one to a published randomised trial in which small, short term changes were observed on a single subscale of a wider mental state assessment; groups contained up to 40 patients each, and significance was at the $\mathrm{P}=0.04$ level. ${ }^{1}$ Confidence intervals were not given.

Given the number of other instruments used in that trial, it is highly likely that the differences attributed to the intervention could have arisen by chance. An independent review of this study and the unpublished data states that two other randomised trials comparing donepezil with placebo, which have not been published, have shown smaller differences between intervention and control groups. ${ }^{2}$

Perhaps the manufacturers of donepezil could provide more convincing evidence of efficacy as a condition for retaining such a prominent advertising slot in the pages of the $B M J$.

Trisha Greenhalgh Senior lecturer

Unit for Evidence-Based Practice and Policy,

UCLMS/RFHSM, Whittington Hospital, London N19 5NF

1 Rogers S, Friedhoff LT. The efficacy and safety of donepezil in patients with Alzheimer's disease: results of a US multicentre, randomized, double-blind, placebo-controlled trial. Dementia 1996;7:293-303.

2 New dementia drug. Bandolier 1997;40:2-3.
$B M$ J should require advertisements to detail actual state of evidence

EDITOR-Gray and Wagner expressed important concerns about advertising for donepezil in the $B M J .{ }^{1}$ Smith's reply doesn't resolve an important tension between the journal's need for advertising revenue and its role as a proponent of evidence based practice.

We can understand the BMJ's perspective that concerns about misrepresentation of products should be dealt with by the Prescription Medication Code of Practice Authority: to take on monitoring of the implicit claims of drug advertisements would require considerable additional resources. However, the $B M J$ could surely review advertising when cogent concerns have been raised. As a case in point, donepezil proves an excellent example. The evidence supporting use of the drug is weak and mostly unpublished, yet the pharmaceutical marketing machinery is in full swing. Although the drug is currently being marketed among specialists, interest is high and promotion among general practitioners is likely to increase.

We have completed a review of available information, which was recently considered by a regional expert advisory panel, the south and west development and evaluation committee. ${ }^{2}$ The committee concluded that in terms of value for money, donepezil is a "borderline" case, yielding small benefits (of debatable clinical importance) at relatively high cost. An editorial on drug treatments for Alzheimer's disease in the $B M J$ earlier this year also highlighted the need for improved diagnostic services and the absence of evidence of any effects of treatment on important outcomes such as institutionalisation. ${ }^{3}{ }^{4}$ Notably absent from the evidence are any robust effects on quality of life, activities of daily living, or long term (beyond six months) benefits of any kind including demands made on caregivers. Given the difficulties likely to be encountered in stopping treatment and the demand for a treatment for this dreadful disease, practitioners are in an unenviable position.

The imbalance in messages from the $B M J$ does not help. On the one hand, readers can refer to a balanced editorial that appeared only once ${ }^{3}$; on the other hand, full page advertisements (in addition to the unavoidable advertisements on the wrapper), which give little impression of clinical uncertainty, appear regularly.

Why shouldn't the $B M J$ require some additional note to be made of the actual state of the evidence in advertisements once readers have taken the trouble to point out potential inconsistencies? In the case of donepezil, at the very least some reference could be made to Kelly et al's editorial. ${ }^{3}$

Ken Stein Senior lecturer in public health medicine Ruairidh Milne Senior lecturer in public health medicine

Lesley Best Research fellow

Wessex Institute for Health Research and Development, Winchester SO22 5DH

1 Gray S, Wagner N. Advertisements for donepezil (Aricept) in the BMJ. BMJ 1997;314:1555-6. (24 May.)

2 Stein K. Donepezil in the treatment of mild to moderate senile dementia of the Alzheimer type (SDAT). Development and 
evaluation committee report. Bristol: NHS Executive South and West, 1997. (www.epi.bris.ac.uk/rd/pub/dec/index.htm) 3 Kelly CA, Harvey RJ, Cayton H. Drug treatments for Alzheimer's disease. BMJ 1997;314:693-4. (8 March.)

4 Meyers BS. Telling patients they have Alzheimer's disease. BMJ 1997;314:321-2.

\section{National policy needs to be set for prescribing of this drug}

EDITOR-Old age psychiatry finds itself at the centre of a void in health spending policy. The licensing of donepezil, the only currently available treatment for the symptoms of dementia, has fallen victim to the whims and financial constraints experienced by health commissions throughout Britain. In Liverpool a budget has been set aside for this potentially important treatment, while in West Surrey general practitioners have been specifically directed by the commission not to prescribe it. Many people in Surrey are paying up to $£ 200$ a month for private prescriptions of this drug (NHS cost $£ 85$ a month), and those who cannot afford the treatment do not receive it.

Donepezil has been shown to have a discernible and appreciable effect on both $\operatorname{cog}_{-}$ nitive and global outcome measures in large clinical drug trials. That it has an effect is not in question. What remains less clear is the value and the quality of the effect, and this can be clarified only by personal experience. While specialists in Liverpool gain important first hand knowledge of the benefits and limitations of this treatment, those in Surrey are denied this vital therapeutic knowledge.

A scandalous and discriminatory situation now exists for people with dementia, which seems to be nurtured by a deep seated popular belief that dementia is untreatable. Such fatalism comes easily to the English (in contrast to the Americans) and is now being exploited by cash strapped health commissions. The lesson that a proactive Department of Health should have learnt by now is that treatments that work reduce dependency and in the end lighten the burden on the state. Such savings are experienced only at regional and national level, and this is another reason why such policies should be coordinated and financed centrally. If donepezil is to be proscribed, rationed, or prescribed freely under the NHS, consistency across Britain is essential.

We are seeing a situation similar to that concerning the patchy and disappearing provision of continuing care beds five years ago. In that case the Department of Health was finally forced to take action after a storm of popular protest.

H Boothby Consultant psychiatrist

S M N Zaidi Consultant psychiatrist

Farnham Road Hospital, Guildford GU2 5LX

V Seth Consultant geriatrician

Royal Surrey County Hospital, Guildford

GU2 5XX

S Khalaf Consultant psychiatrist

H Jameel Consultant psychiatrist

Ridgewood Centre, Old Bisley Road, Camberley GU16 5QE

S Mahomed Consultant psychogeriatrician

Abraham Cowley Unit, Holloway Hill, Lyne,

Chertsey KT16 0QA

Al-Yassiri Consultant psychiatrist

Barnes Hospital, London SW14 8SU

\section{Drug company's reply}

EDitor-Donepezil has been licensed in the United States, Canada, Switzerland, and 14 of the 15 European member states for the symptomatic treatment of mild to moderate Alzheimer's dementia. In a six month study cognition improved (by 4 points on the cognitive portion of Alzheimer's disease assessment scale) in $40 \%$ of a group given $5 \mathrm{mg}$ and $58 \%$ of a group given $10 \mathrm{mg}$, compared with $28 \%$ of a placebo group (pack insert, Eisai, USA). The table shows an analysis of responders from the same study (summary of product characteristics, Eisai, UK).

The Drug and Therapeutics Bulletin ${ }^{1}$ was not willing to review the pivotal phase III studies (data on file (A301 and A302), Eisai, UK) that formed the basis of the regulatory submission or the product information derived from this evaluation. This approach is not helpful to patients or physicians.

Greenhalgh and Stein et al criticise the advertising of the drug. The Code of Practice Authority has investigated two complaints about advertising of donepezil and has found the claims made to be factual and consistent with the licence.

Stein et al's comments about the efficacy data fail to mention that international guidelines for the conduct of trials in dementia have been observed. Acetylcholinesterase inhibitors will help only a small proportion of patients, but this does not mean that those patients should be denied access to them. Perhaps Stein et al should attend the clinic in Southampton where patients were treated in the clinical trials programme and see patients who have benefited from donepezil.

Greenhalgh's comments about the paper in Dementia are correct: we would not have received a licence on the basis solely of these data. The efficacy data from the phase III studies are consistent in showing improved cognition and improvements or stabilisation in global function and activities of daily living. Only quality of life measures failed to show an effect of the drug, and there are no validated tools to use for this measure. The article in Bandolier contained so many errors that it should regarded with extreme caution.

Boothby et al's comments are fair, and the impact of donepezil will be difficult to

Analysis of responders † from United Kingdom summary of product characteristics (six month study)

\begin{tabular}{lcc}
\hline & $\begin{array}{c}\text { Intention to } \\
\text { treat population } \\
(\mathbf{n}=365)\end{array}$ & $\begin{array}{c}\text { Evaluable } \\
\text { population } \\
(\mathbf{n}=352)\end{array}$ \\
\hline Placebo group & $10 \%$ & $10 \%$ \\
\hline Group given donezepil: & & \\
\hline $5 \mathrm{mg}$ & $18 \%^{*}$ & $18 \%^{*}$ \\
\hline $10 \mathrm{mg}$ & $21 \%^{*}$ & $22 \%^{* *}$
\end{tabular}

tResponders were defined as patients showing improvement of $\geqslant 4$ points on cognitive portion of Alzheimer's disease assessment scale, improvement or stabilisation in clinician's interview-based impression of change plus, and stabilisation or improvement in activities of daily living domains of clinical dementia rating scale sum of boxes scale. ${ }^{\star} \mathrm{P}<0.05$. ${ }^{*} \mathrm{P}<0.01$ show when the medicine is not made available to patients. Such outcomes research will be reported with large studies under way in the United States, Canada, and the Nordic countries. Britain does not have prior experience of cholinesterase inhibitors because tacrine was never marketed here This may partly explain the reaction to donepezil from some quarters. The opinion of those who have used the drug is more positive.

P Hooper Director of medical affairs

Eisai, 3 Shortlands, London W6 8EE

A M Whitehead Medical director

Pfizer, Sandwich, Kent CT13 9N

1 Donepezil for Alzheimer's disease? Drug Ther Bull 1997;35:75-6.

\section{Prices charged for private prescriptions} for donepezil show huge variation

EDITOR-It is now some six months since the introduction in Britain of donepezil hydrochloride, the first licensed drug to become available for the symptomatic treatment of patients with mild to moderate Alzheimer's disease. This first but important step in helping patients with a previously untreatable condition has been met with vacillation by the government. The Department of Health has failed to provide guidance to health authorities, and there is currently complete inequity between patients in different parts of Britain. As a result many patients and carers are being forced to obtain the drug with a private prescription. Doctors prescribing donepezil in good faith through this mechanism will be astonished at the mark up being charged by some pharmacists, including some of the most well known high street names.

We contacted 62 chemist shops in Bath and the surrounding areas to find the cost of a one month prescription of donepezil $5 \mathrm{mg}$ and $10 \mathrm{mg}$. The NHS cost is $£ 68.32$ for $5 \mathrm{mg}$ and $£ 95.76$ for $10 \mathrm{mg}$. The prices charged for a private prescription varied from $£ 68.32$ to $£ 120.41$ (mean £98.66) for $5 \mathrm{mg}$ and $£ 95.76$ to $£ 168.78$ (mean $£ 139.18$ ) for $10 \mathrm{mg}$. In general, the lower prices were quoted by local chemists that were not part of a chain.

We understand that the higher figures are nearer to Pharmaceutical Society guidelines, which suggest a $50 \%$ mark up on the actual drug price plus a dispensing fee. These guidelines seem to be more applicable to the pricing of wine by top restaurants than to the health needs of patients with dementia, and such profiteering is surely unacceptable. Doctors would do well to warn patients and carers to choose their pharmacist with care and check the price beforehand.

Roy W Jones Director and honorary consultant geriatrician

Jill B Mann Senior clinical research fellow Samantha A Saunders Research nurse Research Institute for the Care of the Elderly, St Martin's Hospital, Bath BA2 5RP r.w.jones@bath.ac.uk 


\section{Review of drug in Drug and Therapeutics} Bulletin is uninformed

EDITOR-The recent unsigned article about donepezil in the Drug and Therapeutics Bulletin $^{1}$ requires comment, particularly from those of us who have participated in the clinical trials programme for this compound. The bulletin is seen by many doctors as providing balanced, comprehensive reviews. However, it has reached its eccentric conclusion in this case without reviewing the two main efficacy studies that form the basis for the licensing decisions in Britain, the United States, Canada, and other European countries. We acknowledge that the studies are still unpublished, but it cannot be in the best interests of patients to disregard completely the bulk of the clinical information available, and consequently the review is idiosyncratic and uninformed.

The data show that donepezil will provide clinical improvements in cognition $(\geqslant 4$ point improvement in the cognitive portion of the Alzheimer's disease assessment scale) in about $57 \%$ of patients taking $10 \mathrm{mg}$ donepezil over six months (placebo response $30 \%$ ). ${ }^{2}$ In a small number of cases this will extend to the stabilisation or improvement of global function and activities of daily living (22\% of patients taking $10 \mathrm{mg}$ donepezil $v \quad 10 \%$ taking placebo; summary of product characteristics, Eisai, UK).It would have been preferable for the data to be published before the drug was launched-a sentiment that we have expressed to the companies concerned-but they are in the public domain and freely available on request from the medical information departments of Eisai and Pfizer. A paper on one of the two studies is currently in press and consequently has been peer reviewed. ${ }^{2}$ Further papers have been submitted for publication, and it seems highly unlikely that a peer reviewed journal will make a different interpretation from that of the numerous regulatory bodies that have already assessed the data.

We have all seen patients who have shown good responses to donepezil, and it is wrong to deny patients treatment that might help their condition on the basis of an incomplete assessment of the evidence. Donepezil will soon be joined by other effective medicines produced by other companies. The management of Alzheimer's disease has entered a new era. What is required is the responsible introduction of the treatments into clinical practice in a way that ensures careful evaluation and clarification of their potential and limitations.

\section{Signed by 18 authors}

Correspondence to: Dr D Wilkinson,

Faculty of Medicine, Health and Biological Sciences, Thornhill Research Unit, Moorgreen Hospital, Southampton SO30 3JB

1 Donepezil for Alzheimer's disease. Drug Ther Bull 1997;35:75-6.

2 Rogers SL, Farlow MR, Mohs R, Friedhoff LT. A 24 week double blind placebo controlled trial of donepezil in patients with Alzheimer's disease. Neurology (in press).
**The editorial team of the $B M J$ reviews all advertisements before they are published, but we do not peer review them with anything like the rigour that we apply to original research papers. We have four main reasons for adopting this policy.

Firstly, readers are well aware of the difference between advertising and editorial material. They recognise that advertising is not approved by the editors in the way that original papers are. Readers of all publications recognise these differences and, I believe, discount advertising accordingly. Nobody, for example, places the same value on the advertising blurb about a book as they do on an independent review.

Secondly, we are always willing to consider for publication criticisms of advertising material, and we urge readers to write to us with such criticisms.

Thirdly, there are many other bodies responsible for scrutinising advertising and dealing with complaints. We would enter dangerous territory if we began "approving" advertisements with a peer review process. We would then be taking over the job of the Medicines Control Agency and similar bodies, and we are not qualified to do so. Nor are we adequately accountable for such a process.

Fourthly, we don't think that it would be a good use of our resources to spend time peer reviewing advertisements. This is a rationing issue. Our resources, like those of everybody else, are limited, and I believe that they are better spent improving and speeding up our peer review of original research, developing the educational content of the journal, making our editorials still more incisive and relevant, and making the journal more readable. This rationing argument also leads, for instance, to a policy of not sending out proofs of obituaries, something that upsets some authors.EDITOR

\section{Quiet room is needed in hospitals for prayer and reflection}

EDITOR-Prayer has a pivotal role in the life of Muslims. Five times a day, at specified times, a Muslim will turn directly to God to seek guidance and strength in his or her attempt to walk through life upright. The ritual itself is both physical and spiritual as Islam takes a holistic view of life, recognising the need to unify the different facets of human existence.

There are roughly two million Muslims in Britain, many of whom are observant of their prayers. Included among these are a large number of Muslim doctors and other health professionals, who practise in hospitals throughout Britain. Many of these practitioners work in extremely stressful environments, and prayer often has an important role in helping to alleviate such stresses.
For Muslim patients and health professionals who feel the need for prayer, it is unfortunate that many hospitals do not have adequate provision. Those of us who work in hospitals can sometimes locate an unused room or quiet corridor in which to observe this most essential of rituals. Patients and visitors naturally find this much more difficult.

A possible solution to this problem is to have a "quiet room," set aside for prayer or meditation or reflection, which is open to those of any faith or indeed no faith. I am aware that such a facility exists in some hospitals, including my present place of employment. The facility is frequently used by staff, students, and patients alike and is much appreciated. Having such rooms available in hospitals throughout Britain would help to make our hospital services more sensitive to the multicultural needs of the society they serve.

Aziz Sheikh Clinical research fellow

Department of General Practice and Primary Health Care, Imperial College School of Medicine at St Mary's, London W2 1PG

\section{Corrections}

Deaths from cervical cancer began falling before screening programmes were established

An author's error occurred in this letter by A E Raffle (11 October, p 853). The penultimate sentence of the third paragraph begins: "Department of Health statistics show that in England and Wales each year about 800000 women have abnormal smears." The words "each year" should have been omitted. In fact, 800000 is the total number of women with abnormal smears; the number of abnormal smears each year in England is 209446.

Reduction in use of temazepam is factor in deaths related to overdose

An editorial error occurred in this letter by T C Gilhooly (29 November, p 1463): the figure omitted the line showing the percentage of drug misusers using temazepam. The correct figure is published here.

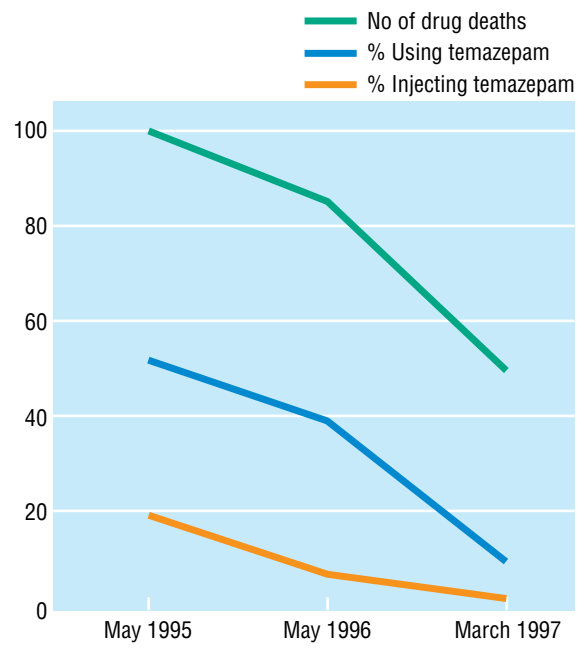

Number of deaths due to drug overdose and percentages of drug misusers using and injecting temazepam 